\title{
Sociabilidades "positivas" em rede: narrativas de jovens em torno do HIV/Aids e suas tensões cotidianas
}

\author{
I ' Luís Augusto Vasconcelos da Silva, 2 Filipe Mateus Duarte, \\ ${ }^{3}$ Gilberto Rios Alves Netto I
}

Resumo: A partir de uma pesquisa qualitativa sobre sociabilidades de jovens vivendo com HIV/ Aids, este artigo pretende trazer algumas reflexões sobre o lugar e importância das novas redes sociais para esse grupo, destacando alguns conflitos, dilemas e tensões cotidianas em torno da doença. Entre os anos de 2012 e 2015, foram identificados e acompanhados grupos de discussão online e redes sociais que agregam pessoas vivendo com HIV/Aids. Neste artigo, através da observação participante e entrevistas semiestruturadas online, destacamos a existência de grupos de suporte online construídos por pessoas vivendo com HIV/Aids, com o objetivo de obterem informação, conselho e apoio, ainda que, para além de seu suporte emocional e de informação, possam reproduzir valores morais. Destaca-se que as biotecnologias têm propiciado novos tipos de sociabilidades e organização social, produzidos a partir de critérios de saúde e características biológicas (somáticas). Novas formas de "mobilização social" estão sendo também viabilizadas através da internet: novos engajamentos e sentidos de pertencimento que parecem ser mais transitórios, pessoais, difusos ou "líquidos". Por sua vez, essas novas formas de sociabilidade mostram também as múltiplas formas de viver com HIV/Aids.

> Palavras-chave: HIVIAids. Jovens vivendo com HIVI Aids. Internet. Biossociabilidade. Cuidado.

\author{
1 Instituto de Humanidades, \\ Artes e Ciências, Universidade \\ Federal da Bahia. Salvador-BA \\ Brasil (luisvascon@uol.com.br) \\ ${ }^{2}$ Instituto de Saúde Coletiva, \\ Universidade Federal da \\ Bahia. Salvador-BA, Brasil \\ (filipemateusduarte@gmail.com). \\ ${ }^{3}$ Instituto de Humanidades, Artes \\ e Ciências, Universidade Federal \\ da Bahia. Salvador-BA, Brasil \\ (gilberto.rios13@gmail.com).
}


Este artigo trata do lugar e da importância das novas redes sociais para jovens vivendo com HIV/Aids, destacando alguns de seus dilemas e tensões cotidianas. Daremos ênfase a algumas narrativas produzidas ao longo de uma pesquisa sobre sociabilidades de jovens vivendo com HIV/Aids (2012-2015), considerando o cenário de "medicalização" e "normalização" do HIV (SQUIRE, 2010), ou seja, das novas biotecnologias e possibilidades de tratamento (DAVIS; SQUIRE, 2010) e de referência à "Aids crônica" (ALENCAR; NEMES; VELLOSO, 2008).

Algumas particularidades, descontinuidades e "rupturas" narrativas em relação ao HIV/Aids (SQUIRE, 2014) foram possibilitadas por mudanças nesse cenário. Squire (2014, p. 281) ressalta que, com o uso da terapia antirretroviral, pessoas soropositivas podem considerar ou fazer sexo desprotegido entre elas, ou mesmo com outras que são soronegativas, "porque suas cargas virais baixas tornam os riscos de infecção muito pequenos". Essas possibilidades interativas são mediadas também pelas novas tecnologias de informação. Alguns homens gays que vivem com HIV, por exemplo, usam a internet para encontrar parceiros também HIV positivo para a realização do sexo anal desprotegido. Davis et al. (2006) argumentam que essa prática online permite a homens gays soropositivos reduzir o risco de transmissão do $\mathrm{HIV}^{1}$, como também evitar a rejeição sexual e o preconceito.

Atualmente, verifica-se também a existência de "grupos de suporte online" para pessoas vivendo com HIV/Aids, no sentido de obterem informação, conselho e suporte (MO; COULSON, 2012), ainda que, para além de seu apoio emocional e de informação, possam reproduzir julgamentos morais (RIER, 2007). Por outro lado, através do engajamento nesses grupos, há outros aspectos importantes a assinalar, por exemplo, maior otimismo em relação à doença e ao futuro e percepção de menor isolamento (MO; COULSON, 2013). Esse último aspecto deve ser ressaltado, na medida em que o estigma do HIV ainda justifica as dificuldades de revelação da condição de HIV positivo para outras pessoas (FLOWERS; DAVIS, 2012), considerando o medo da rejeição e isolamento por seus potenciais parceiros sexuais (JEFFRIES IV, 2015). Como destacam Paiva et al. (2011, p. 4208), não se pode esquecer que as pessoas vivendo com HIV "permanecem significadas como perigosas". 
Parece, então, que as biotecnologias têm propiciado um novo tipo de sociabilidade, que passa a ocorrer a partir de critérios não tradicionais: critérios de saúde, longevidade, características biológicas, performance corporal, etc. Rabinow (1999) chama esse novo modelo social de biossociabilidade. Neste modelo de construção de bioidentidades, o corpo é o lugar da moral e matriz da identidade pessoal (ORTEGA, 2003). Nesse sentido, ser portador de algum traço genético raro, envolver-se em práticas corporais específicas, receber diagnóstico positivo para certos tipos de patologias etc., passam a mobilizar e sustentar formas específicas de vínculos e relacionamentos sociais, bem como reivindicações por direitos e cidadania.

Em sua reflexão sobre essas biossociabilidades, a partir das discussões sobre "cidadania biológica" desenvolvidas por Novas e Rose (2004), Ortega e Zorzanelli (2010, p. 162) pontuam o papel importante que os dispositivos de comunicação têm exercido para a maneira como entramos em contato com os outros: "trata-se de novas formas de cidadania, pela incorporação de doentes em comunidades ligadas eletronicamente por sites, listas de e-mail, fóruns de discussão”.

Certamente, estamos diante de novos efeitos da biopolítica descrita por Foucault (2001), ao destacar uma mudança importante nos mecanismos de poder a partir do século XVII, um deslocamento do direito de morte para um poder que se exerce positivamente sobre a vida. Esse "poder sobre a vida" desenvolveuse sob duas formas principais: uma centrada no corpo como máquina, e outra, mais tarde, por volta da metade do século XVIII, centrada no corpo-espécie, constituindo, respectivamente, dispositivos disciplinares e técnicas de regulação da população. A administração do corpo e a gestão da vida recobrem o que Michel Foucault designa como era do biopoder. Entretanto, no cenário atual, mediado pelas biotecnologias, observam-se mudanças importantes no papel do Estado como regulador da saúde de indivíduos e populações. Como sustentam Ortega e Zorzanelli (2010, p. 73), "notamos um deslocamento do Estado como responsável pelos procedimentos de saúde sobre o indivíduo e a coletividade para uma autogestão da saúde”.

Nesse novo cenário, os sujeitos devem manter o exercício constante da autovigilância e autocontrole em busca da saúde ou corpo perfeito (ORTEGA, 2006). No caso de pessoas vivendo com HIV/Aids, não se pode perder de vista a ideia difundida de que os "corpos infectados pelo HIV" são corpos 
"perigosos", e mais especificamente em relação aos jovens vivendo com HIV, podendo "disseminar o vírus através de uma sexualidade vista como 'exacerbada' e 'descontrolada' pela idade" (CUNHA, 2012, p. 74).

Conforme argumenta Cunha (2012, 2014), é a partir da noção de "perigoso" que uma série de estratégias e "açôes pedagógicas" são desenvolvidas para a "modelação moral" desses jovens. Estratégias estas com o objetivo de formar "sujeitos-modelos" (CUNHA, 2014) no exercício do controle de si. Como "protagonista" e sujeito político-moral (jovem vivendo com HIV), é importante tornar-se multiplicador do discurso da prevenção, sendo capaz de cuidar não apenas de si mesmo (prevenir-se e tratar-se), mas, principalmente, do outro - isto é, viver com HIV/Aids sem disseminar o vírus.

Nessa direção, apesar dos avanços e abordagens biomédicas na atualidade, centradas na testagem/tratamento/redução da transmissão do HIV (UNAIDS, 2014), pretendemos focalizar algumas dificuldades e tensões que persistem no cotidiano de jovens vivendo com HIV/Aids, incluindo as dificuldades e resistências no próprio cotidiano do tratamento e construção de relações afetivo-sexuais. Este artigo, portanto, pretende destacar essas novas formas e possibilidades de interação (online), produção de narrativas de si, compartilhamento de histórias de vida e conexão com o outro, a partir da identidade "positiva" para HIV, mas também considerando as ambiguidades, tensōes e incertezas abertas pelo "viver com HIV/Aids".

\section{A trajetória de pesquisa online: interações mediadas pelas bioidentidades}

A internet tem se apresentado como campo importante de produção textual, possibilitando a leitura de padrões e significados culturais sobre diversos aspectos do cotidiano. Em uma perspectiva geertziana, a internet possibilita a inscrição ou fixação de um discurso social, viabilizando uma atividade de interpretação dos significados socialmente disponíveis (GEERTZ, 1989).

Ressalta-se, assim, que os contextos online e offline estão imbricados, na medida em que os signos que se deslocam na rede online dialogam com a vida social mais ampla. As tecnologias de informação, portanto, não constituem um mundo em si, pois são usadas por atores humanos, concretos, em contextos sociais específicos (SLATER, 2002). Essa ressalva é importante para não colocarmos 
esses contextos (real/virtual) como excludentes ou antagônicos entre si, inclusive porque muitas das relações e vínculos contemporâneos ocorrem e são viabilizados através da internet. Podemos, assim, reconhecer a interação complexa e imbricada entre "mundos" online e offline (MILLER; SLATER, 2004), e, nessa direção, focalizar as transformações mútuas e múltiplas: da tecnologia, dos próprios usuários e de suas culturas. Nessa perspectiva, as tecnologias de comunicação não apenas são usadas de forma heterogênea, com muitos interesses em foco, mas também constituem pessoas (MILLER, 2013). Para além da dicotomia real/virtual, podemos pensar em um "continuum on/offline”, e, dessa maneira, compreender como as "mediações tecnológicas" podem reconfigurar as relações sociais (BELELI, 2015, p.94).

A partir dessa perspectiva, algumas estratégias e técnicas da pesquisa qualitativa foram desenvolvidas com o objetivo de acompanhar e compreender diferentes facetas e aspectos envolvidos nas interações online entre jovens vivendo com HIV/Aids. Em 2012, iniciou-se a pesquisa Sociabilidades de jovens vivendo com HIVIAIDS: repercussóes e efeitos da soroidentidade, com financiamento do CNPq, com o objetivo de compreender as formas e modos de sociabilidade de jovens vivendo com HIV, bem como os sentidos e implicações da soropositividade para suas práticas e interações cotidianas.

Entre os anos de 2012 e 2015, a equipe de pesquisa identificou e acompanhou grupos de discussão online (Orkut ${ }^{2}$, Facebook e grupos do portal UOL), que agregam pessoas vivendo com HIV/Aids, mais precisamente jovens na faixa etária entre 18 e 30 anos. Nesses espaços, privilegiamos algumas estratégias desenvolvidas por Silva $(2008 ; 2010)$, como a observação participante em redes sociais, além das entrevistas semiestruturadas (online) com jovens que se mostrassem receptivos à proposta da pesquisa. No decorrer da pesquisa de campo, foram acompanhadas também algumas atividades para pessoas vivendo com HIV/Aids em um centro de referência do estado da Bahia para diagnóstico e tratamento de HIV/Aids, em Salvador. Neste artigo, entretanto, serão privilegiadas as narrativas oriundas dos grupos (UOL e Facebook) e entrevistas online.

Como estratégia para viabilizar a circulação da "imagem" (proposta) do projeto e dos endereços de contato, optou-se pela confecção de cartazes e postais de divulgação, que foram fixados nas salas de espera de serviços de referência para diagnóstico e tratamento em HIV/Aids, em Salvador-Bahia. Além disso, 
foi realizada a distribuição desse material em outros espaços de sociabilidade, como cinemas, teatros, ONGs etc. Na internet, optou-se pela criação de uma página da pesquisa no Facebook, denominada Sociabilidades Positivas, através da qual se buscou atingir duas metas: produzir e divulgar conteúdos sobre a temática da pesquisa; e atrair possíveis jovens interlocutores, a fim de produzir diálogos e materiais de análise. Foi criado também um e-mail do projeto e um blog explicativo.

No decorrer das conversas online, os pesquisadores da equipe registraram/ explicitaram, na respectiva "janela de conversação" do contato (por exemplo, nas salas de bate-papo do UOL), os objetivos da conversa (pesquisa) e os aspectos éticos considerados, de acordo com a Resolução 196/96, que estabelece diretrizes e normas regulamentadoras das pesquisas com seres humanos (o projeto foi aprovado pelo Comitê de Ética da Escola de Enfermagem/UFBA no do parecer: 194.312).

Foram realizadas 14 entrevistas online com jovens vivendo com HIV/Aids, com idades entre 20 e 30 anos, provenientes de diferentes cidades do país. Dentre os entrevistados, houve apenas uma mulher, que se autodeclarou heterossexual. Entre os homens, todos eram HSH (homens que fazem sexo com homens) e, em sua grande maioria, relataram que vivem com HIV após transmissão sexual (apenas um achava que tinha sido infectado em um procedimento odontológico). As conversas online aconteceram através de dispositivos de mensagem instantânea em redes sociais, tais como Skype, chat do Facebook e bate-papo UOL (salas organizadas em torno do HIV), e aplicativos ("app”) de celular - Whatsapp e Scruff3.

$\mathrm{O}$ acesso aos entrevistados/interlocutores ocorreu através de mensagens sobre a pesquisa nas redes sociais para pessoas vivendo com HIV/Aids ou pela própria solicitação voluntária de seus usuários. No grupo do Facebook, por exemplo, podíamos abordar as pessoas "inbox" (no "chat"), contando-lhes sobre quem "éramos" e sobre o projeto de pesquisa. Aqueles que se interessavam podiam marcar o melhor momento para continuar a conversa. Destaca-se que o principal grupo acompanhado (Rede Nacional de Pessoas Vivendo e Convivendo com HIV/AIDS), no Facebook, não fazia parte da Rede Nacional de Adolescentes e Jovens Vivendo com HIV/Aids (RNAJVHA) e não era concebido apenas para "jovens vivendo", embora, a partir de nossas observaçôes, tenhamos percebido a presença significativa desses jovens, principalmente HSH. O grupo chegou a 
contar com mais de mil membros, espalhados por todo o território nacional. Sua

rotina girava em torno do acolhimento de novos membros e do compartilhamento de experiências pessoais, dúvidas sobre o tratamento antirretroviral e informações acerca do HIV/Aids.

As entrevistas foram orientadas por "tópicos-guia" sobre diferentes aspectos da vida cotidiana desses jovens, como as dinâmicas relacionais e afetivo-sexuais, as práticas cotidianas e os sentidos da soropositividade. O tempo de cada entrevista variou de acordo com o dispositivo utilizado e com a disponibilidade de cada interlocutor. Algumas conversas, com o mesmo interlocutor, desdobraram-se em momentos diferentes. A partir de uma perspectiva dialógica e conversacional, a entrevista, aqui, foi considerada como uma ação interativa (PINHEIRO, 1999) que ocorre em um espaço de negociação. Nessa perspectiva, entrevistado e entrevistador são interlocutores do discurso, engajando-se, portanto, em diferentes posicionamentos.

Algumas dessas entrevistas foram viabilizadas também através da mediação de um psicólogo de um Centro de Testagem e Aconselhamento (CTA) em Salvador. Graças a ele, alguns jovens vivendo com HIV, usuários do serviço, puderam entrar em contato, pelo celular, com um dos membros da pesquisa.

Uma vez que esses contatos se mostravam interessados e aceitavam participar da pesquisa, perguntava-se sobre o lugar preferencial para a realização da entrevista: por Facebook ou Whatsapp. A decisão da entrevista online levou em consideração fatores como disponibilidade temporal e/ou geográfica, além de ser uma maneira de registrar instantaneamente a conversa.

No momento da entrevista, dava-se a opção de responder as perguntas via mensagem de texto ou mensagem de voz, recursos que ambas as redes oferecem. Não raro, os entrevistados alternavam a maneira como respondiam: em respostas mais curtas, davam preferência pelo texto; as mensagens de voz quase sempre foram usadas quando buscavam mais detalhes na narrativa. Ao final da conversa, o entrevistador transcrevia as mensagens de voz, a fim de facilitar a análise do material e adequá-lo ao programa usado para esse fim - o QSR NVivo (software utilizado para análise de dados não estruturados).

No que diz respeito às análises dos textos/narrativas produzidos, foi realizada leitura exploratória de todo o material produzido e arquivado, bem como categorização das entrevistas com auxílio do programa QSR NVivo. Com 
esse recurso, buscou-se visualizar a "rede" de categorias (temas), seus pontos de ligação, bem como a sequência dos segmentos de texto. Para evitar alguns problemas no processo de codificação de textos, distintas estratégias analíticas foram articuladas: 1) desenvolvimento de uma leitura exploratória e focalizada dos dados (entrevistas) com o objetivo de criar e identificar categorias analíticas, relacionando-as aos segmentos de texto; 2) desenvolvimento de uma hermenêutica que fosse capaz de contemplar os interlocutores e as condições de produção dos textos (neste caso, considerando os signos e repertórios interpretativos utilizados na própria internet). $\mathrm{O}$ conceito de repertório interpretativo é aqui utilizado para designar a variabilidade de estratégias discursivas, situadas em contextos diversos, para dar sentido ao mundo. Em outras palavras, o conjunto de conceitos, termos, vocabulários, descriçōes, figuras de linguagem etc, que demarcam o campo de possibilidades de construções discursivas (SPINK; MEDRADO, 1999).

Finalmente, para além de encontrar padrões narrativos, buscamos também pensar e reconhecer as narrativas como possibilidades de rupturas e descontinuidades, como "momentos de excepcionalidade". Nessa perspectiva, de acordo com Squire (2014, p. 278), "momentos de excepcionalidade muitas vezes podem ser reconhecidos inclusive nas narrativas mais convencionais".

\section{Narrativas online: desdobramentos a partir do HIV/Aids}

A partir do acompanhamento de grupos online e das nossas conversas com jovens vivendo com HIV/Aids, gostaríamos de destacar algumas características e possibilidades abertas por esses "espaços" interativos. Conforme alguns relatos e nossas observações, diversos aplicativos e páginas virtuais têm propiciado às pessoas vivendo com HIV/Aids buscarem encontros, contatos e troca de experiências. Para alguns dos nossos interlocutores, as ferramentas de interação online possibilitam a criação de laços de amizade, aproximação e diálogo com outras pessoas soropositivas. $\mathrm{M}_{+}, 29$ anos, por exemplo, utiliza o aplicativo de celular Scruff e o bate-papo UOL. Sobre essa última página, fez a seguinte consideração: "acho acolhedor... saber que está conversando com gente que compartilha de algo em comum"4. De acordo com esse jovem, nas salas de batepapo e nos aplicativos ("apps"), é possível encontrar outras pessoas a partir de "nicknames" relacionados à soropositividade, como "poz" (em inglês), "pos", "HIV+”, “+”, “positivo”, "positividade”. 
$\mathrm{Na}$ página do UOL, existem inúmeras salas de bate-papo onde é possível encontrar pessoas por cidades e regiões, mas também por faixa etária, orientação sexual ou temas de interesse. Em salas organizadas em torno do tema "HIV", seus usuários podiam conversar abertamente sobre o assunto, assim como discutir os modos de funcionamento dos medicamentos que faziam uso, suas dificuldades e estratégias para superá-las:

- A+ fala para B+: e a tontura do efavirenz passou?

- B+ fala para A+: eu não tomo o efavirenza meses

- B+ fala para A+: parei de tomar por conta própria

- A+ fala para $\mathrm{B}+$ : ta tomando oque entao?

- B+ fala para A+: tenofovir e lamivudina

- A+ fala para B+: mas e ae zerou?

- B+ fala para A+: não adaptei com o efavirenz

- B+ fala para A+: preciso dirigir ou pilotar todo os dias e ele deixava ruim a minha coordenação motora e reflexos

(Trecho de conversa entre usuários no Bate Papo UOL - HIV) ${ }^{5}$.

Seus usuários podem, portanto, conversar sobre suas vidas cotidianas e, também, sobre suas rotinas de uso da terapia antirretroviral, utilizando-se de nomenclaturas e termos biomédicos e farmacológicos para definirem o que estão sentindo ou como procedem na administração de suas rotinas atravessadas pelo HIV. Essas observaçôes corroboram com as ideias de autores, como Ortega (2008) e Rabinow (1999), que sinalizam como a cultura científica da biotecnologia vem "inaugurando" subjetividades que se apropriam dos jargões médicos para definir seus estados corporais, emocionais etc.

É importante enfatizar que, em nossas observações da rotina das salas, pudemos perceber que alguns usuários já se conheciam e, aparentemente, reconheciam-se através dos "nicks" utilizados. Esse procedimento lhes permitia retomar conversas anteriores, como exemplificado no trecho de conversa sobre a administração dos medicamentos Efavirenz, Tenofovir e Lamivudina. Outro ponto interessante é que as salas constituem parte da rotina dessas pessoas que, geralmente, circulam nelas no período da noite; ao que parece, sem combinação prévia. As temáticas que circulam nesse espaço vão desde a busca por encontros sexuais entre pessoas soroconcordantes (com a mesma sorologia para HIV) ou sorodiscordantes, até a busca por informações sobre o HIV, uso dos medicamentos e promoção de comportamentos de autocuidado. 
Em se tratando do uso das terapias antirretrovirais, não podemos negligenciar o fato de que há também "tensões" geradas mediante os diferentes efeitos da própria terapia. Não é surpresa, portanto, que as pessoas dialoguem no sentido de procurarem a combinação de medicamentos com menos efeitos colaterais ou sugestôes de "medidas" que tenham como objetivo minimizar os efeitos negativos da própria doença. Esse é um aspecto do processo "contínuo" do cuidado (MOL, 2008) que passa a fazer parte do cotidiano de pessoas vivendo com HIV/Aids, ainda que haja diferenças importantes em relação a outras doenças crônicas, por exemplo: a Aids encontra-se associada à ideia de "sexualidades promíscuas" (SQUIRE, 2010, p. 409), corpos perigosos (CUNHA, 2012); consequentemente, a revelação da soropositividade é vinculada às ideias de "honestidade" ou “integridade" (FLOWERS; DAVIS, 2012, p. 720).

Outra forma de alguns jovens encontrarem apoio é através dos movimentos sociais e de direitos civis, como é o caso da Rede Nacional de Adolescentes e Jovens Vivendo com HIV/Aids (RNAJVHA), que possibilita que jovens soropositivos de todo o Brasil se reúnam a fim de promoverem atuaçōes "protagonistas", negando a rotulação de enfermo em favor da posição de pessoa, investida de direitos e identidade própria. Os integrantes da RNAJVHA compartilham histórias e projetos de vida, planejam ações, monitoram e participam de discussões sobre políticas públicas em encontros presenciais e através das redes sociais e, juntos, enfrentam dilemas pessoais e coletivos.

Parte da equipe de pesquisadores teve a oportunidade de ingressar em um dos grupos no Facebook para pessoas vivendo e convivendo com HIV/Aids, como discutido na seção anterior. O ingresso foi possível através do convite de seus próprios membros. Destaca-se que um dos pesquisadores do projeto conheceu um desses membros na sala de bate-papo "HIV" do UOL. Nesse grupo do Facebook, seus membros podiam criar e participar de todas as publicações, responder uns aos outros e "curtir" suas publicações, criando uma forma de diálogo. Ressaltase, entretanto, que a entrada, visualização e participação na página/grupo só ocorriam quando um membro ativo do grupo adicionava o convidado, devendo o moderador aceitá-lo e apresentar-lhe as "regras do grupo".

Considerando as interaçōes no Facebook, é importante enfatizar que, em vários momentos, aparecem nos espaços de sociabilidade construídos por pessoas e "jovens vivendo" relatos sobre autocuidado e autorresponsabilidade. Um dos 
aspectos dessa "autovigilância” diz respeito à preocupação com um estilo de vida considerado adequado, com adoção de práticas esportivas e alimentação saudável, assim como à adesão ao tratamento antirretroviral (TARV). Se, por um lado, a adesão ao tratamento antirretroviral é visto nesses grupos como uma responsabilidade individual, por outro, a não adesão pode ser apontada como uma (possível) "falha moral" ou "falta de responsabilidade" consigo mesmo. Nessa direção, as trocas de mensagens, experiências e histórias de superação parecem ter também como objetivo mostrar aos interlocutores que é possível "mudar" ou "manter" determinados comportamentos. Essa discussão aparece em muitos dos relatos juvenis que identificamos no grupo do Facebook:

Olá, galera, meu nome é W+, tenho 21 anos, sou soro positivo há 1 ano e meio, comecei a tomar Retrovirais há 6 meses, a adesão foi difícil assim como o período de transição, foi muito difícil pra mim [...] o HIV servio como alerta da falta de responsabilidade que eu tinha comigo, e tem moldado meu caráter para melhor, amadureci como nunca na vida. Quero agradecer por ter me adicionado ao grupo, e desejo tudo de bom a todos. Beijos.

(W+., 21 anos, Facebook, novembro de 2013)

O coquetel permitiu um controle maior do vírus e obviamente também traz algumas consequências, afinal não é fácil lidar com os [efeitos] colaterais. Às vezes eles só se manifestam nos exames alterando algumas taxas, o que exige do soropositivo uma vida que inclua alimentação saudável e atividades físicas. Essa mudança de comportamento auxilia no controle das taxas e retarda o aparecimento da lipodistrofia [distribuição patológica da gordura corporal em função do uso dos antirretrovirais]. Não vou dizer que nunca pensei em parar de tomar a medicação. Isso já veio um milhão de vezes na minha cabeça, especialmente nos dias mais difíceis e solitários. Especialmente quando me percebo diferente.

(S+, 29 anos, Facebook, novembro de 2013)

Por sua vez, a partir do compartilhamento das informações sobre carga viral $(\mathrm{CV})$ e células $\mathrm{CD} 4$, essas pessoas produzem sentidos sobre seus próprios corpos. Conhecer a numeração de sua carga viral e de seu CD4 funciona como um "espelho" no qual essas pessoas podem se reconhecer: medir sua saúde. O objetivo do tratamento antirretroviral é o de fazer ter uma carga viral muito baixa (indetectável) e uma contagem de células CD4 alta; logo, há um trabalho de administração e vigília sobre o próprio corpo, através das biotecnologias, a fim de se alcançar essa meta e "normalizar" sua vida:

Quase 1 mês e meio de tratamento EFA+LAMI+TENO:

Tonteira apenas de madrugada.

CD4: 906 
Carga Viral: "não foram encontradas cópias de HIV-1"

Triglicérides: 270.

- (C) se sentindo muito feliz.

(C+, 30 anos, Facebook, agosto de 2013)

Tomo meus medicamentos desde dezembro... Em fevereiro minha CV já estava zerada e meu CD4 com mais de 1000. Voltei a me relacionar sexualmente com outros caras apenas depois disso. (L+, 30 anos, Facebook, julho de 2013)

Aaahh, como vcs ja sabem estou indetectavel, mas o q quero falar é q o exame de cd4 ficou pronto .... 1274.....Cd4 de campeão ..... Beijinho no ombro pro hiv passar longe..... $=*$

Ta vendo gente, o melhor é tomar os remédios! Nao tenham medo, dá enjôo, sim, mas passa....

Obs: cd4 de adulto varia entre 500 a 1400.

(J+, 26 anos, Facebook, junho de 2014)

\section{Autobiografias, acolhimento e narrativas (im)pertinentes}

No caso específico da Aids, pode-se dizer que indivíduos que antes do diagnóstico nada tinham em comum agora encontram no próprio corpo um "marcador" que os agrega, que os mobiliza para a formação de uma coletividade. O sentimento de pertencimento a esse grupo (de pessoas vivendo com HIV/ Aids), ainda que não seja unidirecional, na medida em que existem trajetórias de vida (e infecção) diferentes para cada sujeito, emerge a partir do diagnóstico de sorologia positiva para HIV e é vivenciado, dentre outros aspectos, no cotidiano de idas ao ambulatório médico, no aprendizado e compartilhamento de termos médicos que instrumentalizam a leitura sobre a própria condição sorológica (CD4, carga viral, sistema imunológico, adesão ao tratamento, profilaxia pré e pós-exposição etc.) e na construção e apropriação da categoria "pessoa vivendo" e "jovem vivendo" como expressões de suas identidades.

Em relação a esse sentimento de "pertencimento" (e "acolhimento" no grupo), é importante considerar a condição socialmente estigmatizada, depreciativa e marginalizada que as pessoas soropositivas para HIV continuam a vivenciar. Entretanto, isso não significa que o mesmo grupo que acolhe não possa reproduzir conflitos morais, ou mesmo que, nesses grupos, como sinaliza Goffman (2015, p. 47), ao falar sobre a "ambivalência de vinculação do indivíduo com a sua categoria estigmatizada", não possam ocorrer "oscilações no apoio, identificação e participação que tem entre seus pares”. Ambivalência, aqui, no 
sentido de que a pessoa estigmatizada deve aceitar outros como seus "iguais", ao tempo em que não acredita que alguns "atributos" daqueles outros possam estar associados ao seu caso.

Nessa direção, gostaríamos de trazer um último aspecto sobre os interesses e narrativas que aparecem no decorrer das interações online. No Facebook, por exemplo, muitas mensagens são autobiográficas, no sentido de falarem de si, contarem suas histórias de descoberta do HIV e repercussões atuais em seu cotidiano, ao mesmo tempo em que possibilitam a seus participantes sentirem-se "conectados" e ligados afetivamente, encontrando convergências e pontos comuns entre histórias (coletivas). No grupo, um jovem de 24 anos pode pedir ajuda, em um momento de descoberta recente de sua sorologia positiva, quando "dor, tristeza, arrependimento, medo, insegurança e culpa são todos os sentimentos misturados dentro do coração”. Entre os pares, as mensagens buscam dar o acolhimento e demonstração de possibilidades de superação a partir de uma experiência comum, na medida em que não se está "só nessa”, já que sabem o que ele "está sentindo".

Poder falar com outros que vivem uma situação e experiência similar, que podem compartilhar uma identidade (soropositiva), também pode ajudar a encontrar e produzir maneiras/estratégias para interagir com outros que não sabem de sua condição sorológica e que podem ser soronegativos. Mais precisamente, estar ali com seus "iguais" será importante para saber o que fazer, por exemplo, na seguinte situação: quando se está gostando de "uma pessoa" e ela "está muito a fim de ter um relacionamento sério", mas não sabe que [ele] "é soropositivo". Enfim, tem "vontade de namorar", mas tem "medo de ter algo", tudo devido à "situação" em que se encontra. Nesse cenário, acolhimento e namoro fazem parte de um espectro de opções ou práticas possíveis do grupo, mas que não ocorrem de forma muito tranquila. Há tensões e conflitos entre pessoas/jovens vivendo com HIV que voltam a aparecer no grupo, uma situação ou prática indesejável ("sexo casual"/"sexo fácil”) que insiste em voltar, mas que precisa ficar fora, em outro lugar:

É triste ver pessoas daqui da rede me adicionando, falando sobre a rede e a sorologia ao mesmo tempo que pergunta "o que curte", se curto isso ou aquilo! tenho noção da forma como adquiri hiv, e foi nessa proposta de "sexo casual", sexo facil. usar esse ambiente de acolhimento argumentando "nao sou santo" é revoltante, ainda mais porque eu sei o porque estou nessa condição... eh deprimente! [...] vem pessoas que ainda nao se tocaram e vem fazer de um grupo de acolhimento um grupo de sexo fa- 
cil. por favor, scruff e grindr ta ai! bate papo uol tambem. há vários apps pra isso, mas por favor, façam isso em outro lugar e nao utilizem da minha condição soropositiva, semelhante a sua, para se aproximar e querer sexo facil!!!!!!!!!!!

Portanto, apesar do avanço das terapias antirretrovirais, tornando a carga viral indetectável, ainda há dilemas no cotidiano de jovens vivendo com HIV/Aids, principalmente em relação ao exercício da sexualidade, quando ainda podem ser percebidos como perigosos, irresponsáveis ou potenciais "transmissores" do vírus HIV. Pudemos, também, acompanhar alguns desses dilemas e dificuldades em nossas entrevistas online. Vale a pena destacar a narrativa de um dos nossos interlocutores, jovem de 22 anos, que apontou algumas de suas dificuldades ou barreiras para a participação em grupos de interação online, principalmente quando alguns "assuntos desnecessários" (por exemplo, "fotos de pessoas seminuas") aparecem nesses espaços, ou mesmo quando determinados assuntos (efeitos de medicamentos, vida social, namoro) podem antecipar algum sofrimento no futuro:

[...] Coisas supérfluas que eu acho desnecessárias, que não precisaria colocar no grupo. Ou então fotos de pessoas seminuas.[...] Eu pensava que o assunto dominante seria o HIV/Aids. E alguns assuntos mexem comigo. Por exemplo, "ah, estão surgindo algumas manchas no meu corpo" ou "estou passando super mal depois que tomei a medicação"... enfim, tudo isso eu acho que vai acontecer comigo. Eu acho que não estou sentindo nada no momento, mas porque alguém colocou que está passando por aquilo, por certo problema, enfim... eu imagino que vá acontecer comigo e fico extremamente preocupado. Então, às vezes, eu prefiro não saber o que essas outras pessoas estão passando do que ficar imaginando mil coisas que possam vir a acontecer comigo também. E um assunto que mexe bastante comigo, que apesar de eu estar namorando, é que sempre tem alguém que coloca a questão relacionada à vida social. Alguém coloca "estou conhecendo alguém, não sei como contar, está sendo bastante difícil para mim porque a sociedade geralmente é preconceituosa, eu não sei como a pessoa vai lidar com situação depois que eu contar"... então isso mexe muito comigo. Mas eu fico imaginando se fosse comigo, o que eu faria porque como eu ainda não consegui me conformar seria bem difícil para mim conhecer alguém e ter que lidar com essa situação que de ter que contar para a pessoa. Então isso seria bem complicado. Quando eu vejo as pessoas colocando isso eu penso que já é difícil pro - vamos dizer assim - do homossexualismo que é a maior parte dos soropositivos, então a gente já sofre tanto preconceito, então seria mais um preconceito que é a questão de lidar com a sociedade em si. Esses assuntos me deixam bem balançado. (A+, 22 anos, gay, Salvador, WhatsApp, 2015).

Nessa direção, vale a pena trazer também outro relato de um interlocutor de 25 anos que se colocou de forma "ambivalente" em relação a esses espaços 
de interação. Se, por um lado, as redes sociais, por exemplo, UOL, podem ser importantes para conversar com pessoas que vivam "a mesma realidade", ou buscar "um desconhecido para partilhar algumas angústias", por outro lado, podem mobilizar outros sentimentos desagradáveis pela possibilidade de se deparar com assuntos de sexo e relacionamento. Esse interlocutor falou sobre sua "fase dark" após a descoberta do HIV, sobre seu "bloqueio" para conhecer alguém e sua irritação com "nicks de putaria":

Desde que comprei um Android [...]

No começo, buscava pra arrumar um relacionamento

Passei pela fase "dark" quando descobri o HIV e exclui... E quando voltei, voltei esculhambando qualquer um que chegasse falando só putaria pra mim[...].

As vezes entro no chat da Uol, na sala de soropositivos pra conversar com alguém que tenha a mesma realidade que eu, mas o povo de lá me irrita muito, aí nem sempre entro [...]porque o povo só fala merda, só vejo nicks de putaria, essa promiscuidade toda, me deixa pra morrer (D+, 25 anos, gay, Rio de Janeiro, Facebook, 2014)

Há, assim, temas ou conversas que geram desconforto entre alguns participantes dos grupos online. Apesar de poder ser um "espaço" importante para pessoas que compartilham um mesmo "atributo" (o HIV), nem tudo é possível de ser dito, lido ou revelado, o que demonstra a persistência de dificuldades e reprodução de valores (morais) entre seus próprios participantes. É o caso, por exemplo, de interesses, imagens ou histórias veiculados sobre "sexo", corpos e namoro. Esses "espaços" de interação online são também "zonas" de tensão. Nesse sentido, se algumas dessas mensagens podem adquirir um significado positivo para alguns, para outros, pode indicar ou antecipar uma possível vulnerabilidade (no presente) ou dificuldade no futuro.

\section{Considerações finais: sobre "ontologias" abertas}

O acompanhamento de grupos online e interações com usuários de redes sociais possibilitaram-nos produzir um espaço de debate e reflexão importante sobre aspectos atuais do HIV/Aids. Entre estes, destacam-se as novas possibilidades de interação para pessoas/jovens vivendo com HIV. Nesse sentido, há de se considerar o avanço no tratamento antirretroviral, característico da terceira fase da epidemia da Aids, que hoje possibilita que as pessoas vivam com HIV e tenham melhores perspectivas de vida. Ou seja, mudou-se a percepção da infecção como 
"atestado" de doença terminal, sem cura, para uma condição de doença crônica, controlável. Entretanto, nesse cenário, há também implicações ou dilemas éticos (DAVIS, 2010) produzidos a partir das novas terapias antirretrovirais; quando, por exemplo, as pessoas começam a regular ou organizar suas relações sexuais (interrupção/continuação) a partir das categorias biomédicas (carga viral "zerada", "indetectável” etc.) e das informaçôes técnicas conhecidas e disponibilizadas.

Por outro lado, para além da "normalização" da Aids (SQUIRE, 2010; FLOWERS, 2010), conforme também alguns dos nossos relatos, não se pode negligenciar o fato de que a revelação da soropositividade continua sendo um processo difícil que envolve o medo do estigma social, da rejeição, sentimento de culpa e vergonha, situação que pode justificar a procura por alguém com a mesma condição sorológica para se relacionar. Sem dúvida, essa discussão é relevante para destacar o papel que a internet e suas redes sociais passam a ter para determinados grupos/identidades contemporâneas.

É importante enfatizar que as “identidades clínicas” (VALLE, 2002; 2010), como é o caso das pessoas que são diagnosticadas como soropositivas para HIV, estão também vinculadas às novas formas de mobilização social, especialmente através de redes políticas e de apoio, ONGs/Aids, redes sociais de relacionamento na internet, etc. Dessa forma, é possível colocar em evidência o aspecto político das identidades, já que categorias são usadas e propagadas a fim de que indivíduos identifiquem a si mesmos como pertencentes a determinados grupos e, assim, seja possível o investimento em ações protagonizadas por eles mesmos (reivindicações por políticas públicas, por exemplo).

Entretanto, conforme discutimos neste artigo, não podemos negligenciar as mudanças no cenário atual das biopolíticas, na medida em que se destaca a autogestão da saúde e do cuidado. Certamente, essa autogestão também não ocorre de forma neutra e sem efeito (moral) para aquelas pessoas que não conseguem aderir às prescrições de regras e condutas, ou mesmo para aquelas que seguem outras direções.

Por outro lado, também não podemos esquecer essas novas formas de mobilização (e pertencimento) social que passam a existir a partir e através da internet. Novos engajamentos e sentidos de pertencimento que parecem ser mais transitórios, pessoais, difusos ou "líquidos" (BAUMAN, 2001). Vale destacar que essas mudanças e associações de novos elementos/atores nos fazem pensar 
também sobre os novos "papéis" do Estado e do próprio movimento social, quando consideramos os vários aspectos (e dificuldades) envolvidos no cuidado às pessoas vivendo com HIV/Aids, entre eles, a demora na marcação de consultas e o medo de ser reconhecido como HIV positivo (SILVA; SANTOS; DOURADO, 2015).

Todas essas discussões e desdobramentos das narrativas que aqui foram focalizadas mostram também as múltiplas formas (complexas), abertas e incertas de viver com HIV. Múltiplos efeitos a partir da associação e interação de muitos atores (pessoas, tecnologias, entidades, tratamentos, crenças, símbolos etc.). Tudo isso nos faz pensar em "ontologias" abertas, múltiplas, "políticas" (MOL, 1999; 2002), no sentido de que as condiçôes de possibilidade não estão dadas, ou seja, a realidade é "manipulada" através de muitas ferramentas; ela é "feita" e "performada" no decurso das práticas; portanto, mais do que singular, “intocada no centro”, ela é múltipla (MOL, 1999, p. 77). Certamente, o surgimento e interação de novos elementos/atores produzirão mais narrativas e, consequentemente, a necessidade de novos estudos em HIV/Aids. ${ }^{6}$

\section{Referências}

ALENCAR, T.M.D.; NEMES, M.I.B.; VELLOSO, M.A. Transformações da "Aids aguda" para a "Aids crônica": percepção corporal e intervenções cirúrgicas entre pessoas vivendo com HIV e Aids. Ciênc. Saúde Coletiva, v. 13, n. 6, p. 1841-1849, 2008.

BAUMAN, Z. Modernidade líquida. Rio de Janeiro: Jorge Zahar, 2001.

BELELI, I. O imperativo das imagens: construção de afinidades nas mídias digitais. Cadernos Pagu, v. 44, p. 91-114, 2015.

CUNHA, C. Os muitos reveses de uma "sexualidade soropositiva": o caso dos jovens vivendo com HIV/Aids. Sexualidad, Saludy Sociedad, v. 10, p. 70-99.2012.

Modos de fazer sujeitos na política de AIDS: a gestão de jovens vivendo com HIV/ Aids. Século XXI, Revista de Ciências Sociais, v. 4, n. 2, p. 91-131, 2014.

DAVIS, M. et al. Sex and the internet: gay men, risk reduction and serostatus. Culture, Health \& Sexuality, v. 8, n. 2, p. 161-174, 2006.

Antiretroviral treatment and HIV prevention: perspectives from qualitative research with gay men with HIV in the UK. In: DAVIS, M.; SQUIRE, C. HIV treatment and prevention technologies in international perspective. UK: Palgrave Macmillan, 2010. p. 126-143. DAVIS, M.; SQUIRE, C. HIV Technologies. In: HIV treatment and prevention technologies in international perspective. UK: Palgrave Macmillan, 2010, p. 01-17. 
FLOWERS. P. HIV transitions: consequences for self in an era of medicalization. In: DAVIS, M.; SQUIRE, C. HIV treatment and prevention technologies in international perspective. UK: Palgrave Macmillan, 2010, p.109-125.

FLOWERS, P.; DAVIS, M. Understanding the biopsychosocial aspects of HIV disclosure among HIV-positive gay men in Scotland. Journal of Health Psychology, v. 18, n. 5, p. 711724, 2012.

FOUCAULT, M. História da sexualidade 1: a vontade de saber. Rio de Janeiro: Graal, 2001. GEERTZ, C. A interpretação das culturas. Rio de Janeiro: LTC, 1989.

GOFFMAN, E. Estigma: notas sobre a manipulação da identidade deteriorada. Rio de Janeiro: LTC, 2015.

JEFFRIES IV, W. et al. HIV stigma experienced by young men who have sex with men (MSM) living with HIV infection. AIDS Education and Prevention, v. 27, n. 1, p. 58-71, 2015. MILLER, D.; SLATER, D. Etnografia on e off-line: cybercafés em Trinidad. Horizontes Antropológicos, v. 21, p. 41-65, 2004.

MILLER, D. Trecos, troços e coisas: estudos antropológicos sobre a cultura material. Rio de Janeiro: Zahar, 2013.

MOL, A. Ontological politics. A word and some questions. In: LAW, J; HASSARD, J. (Org.). Actor network theory and after. Oxford, UK: Blackwell, 1999. p.74-89.

. The body multiple: ontology in medical practice. Duke University Press, 2002.

The logic of care: health and the problem of patient choice. London and New York: Routledge, 2008.

MO, P.K.H.; COULSON, N.S. Developing a model for online support group use, empowering processes and psychosocial outcomes for individuals living with HIV/AIDS. Psychology and Health, v. 27, n. 4, p. 445-459, 2012.

. Online support group use and psychological health for individuals living with HIV/AIDS. Patient Education and Counseling, v. 93, p. 426-432, 2013.

NOVAS, C.; ROSE, N. Biological citizenship. In: AIHWAONG; COLLIER, S. (Org.) Global Assemblages: technology, politics, and ethics as anthropological problems. Oxford: Blackwell Publishing, 2004. p. 439-463.

ORTEGA, F. Práticas de ascese corporal e constituição de bioidentidades. Cadernos de Saúde Coletiva, v. 11, n. 1, p. 59-77, 2003.

. Das utopias sociais às utopias corporais: identidades somáticas e marcas corporais. In: ALMEIDA, M.I.M; EUGENIO, F. (Org.). Culturas Jovens: novos mapas do afeto. Rio de Janeiro: Jorge Zahar, 2006. p. 42-58.

O corpo incerto: corporeidade, tecnologias médicas e cultura contemporânea. Rio de Janeiro: Garamond, 2008. 
ORTEGA, F.; ZORZANELLI, R. Corpo em evidência: a ciência e a redefinição do humano.

Rio de Janeiro: Civilização Brasileira, 2010.

PINHEIRO, O.G. Entrevista: Uma Prática Discursiva. In: SPINK, M.J.P (Org.). Práticas discursivas e produção de sentidos no cotidiano: aproximações teóricas e metodológicas. São Paulo: Cortez Editora, 1999. p. 183-214.

PAIVA, V. et al. A sexualidade de adolescentes vivendo com HIV: direitos e desafios para o cuidado. Ciência \& Saúde Coletiva, v. 16, n. 10, p. 4199-4210, 2011.

RABINOW, P. Artificialidade e iluminismo: da sociobiologia à biosociabilidade. In: . Antropologia da Razão. Rio de Janeiro: Relume-Dumará, 1999. p.135-158.

RIER, D.A. Internet social support groups as moral agents: the ethical dynamics of HIV + status disclosure. Sociology of Health \& Illness, v. 29, n. 7, p. 1043-1058, 2007.

SLATER, D. Making things real: ethics and order on the internet. Theory, Culture \& Society, v. 19, n. 5-6, p. 227-245, 2002.

SILVA, L. A. V. Desejo à flor da tel@: a relação entre risco e prazer nas práticas de barebacking. Tese (Doutorado) - Programa de Pós-Graduação em Saúde Coletiva, Universidade Federal da Bahia, Salvador, 2008, fls. 197.

A cibersexualidade e a pesquisa online: algumas reflexôes sobre o conceito de barebacking. Interface: Comunicação, Saúde, Educação, v. 14, n. 34, p. 513-527, 2010.

SILVA, L. A. V; SANTOS, M.; DOURADO, I. Entre idas e vindas: histórias de homens sobre seus itinerários ao serviço de saúde para diagnóstico e tratamento de HIV/Aids. Physis: Revista de Saúde Coletiva, v. 25, n. 3, p. 951-973, 2015.

SPINK, M.J.P.; MEDRADO, B. Produção de sentidos no cotidiano: uma abordagem teórico-metodológica para análise das práticas discursivas. In: SPINK, M.J.P (Org.). Práticas discursivas e produção de sentidos no cotidiano: aproximaçōes teóricas e metodológicas. São Paulo: Cortez Editora, 1999. p. 41-61.

SQUIRE, C. Being naturalised, being left behind: the HIV citizen in the era of treatment possibility. Critical Public Health, v. 20, n. 4, p. 401-427, 2010.

SQUIRE, C. O que é narrativa? Civitas, v. 14, n. 2, p. 272-284, 2014.

TERTO JR., V. Diferentes prevenções geram diferentes escolhas? Reflexões para a prevenção de HIV/AIDS em homens que fazem sexo com homens e outras populações vulneráveis. Rev. Bras. Epidemiol., v. 18, supl. 1, p.156-168, 2015.

UNAIDS. 90-90-90. An ambitious treatment target to help end the AIDS epidemic. New York, 2014.

VALLE, C.G. Identidades, doença e organização social: um estudo das "Pessoas Vivendo com HIV e AIDS". Horizontes Antropológicos, v. 8, n. 17, p. 179-210, 2002.

. Corpo, doença e biomedicina: uma análise antropológica de práticas corporais e de tratamento entre pessoas com HIV/Aids. Vivência, v. 35, p. 33-51, 2010. 
${ }^{1}$ Para além das novas tecnologias biomédicas de prevenção, como PeP e PrEP, há outros "métodos" preventivos, "comportamentais", já utilizados por homens que fazem sexo com homens (HSH) para reduzir o risco de infecção ou transmissão do HIV. Ver, por exemplo, em Terto Jr. (2015).

${ }^{2}$ Até sair de circulação, em outubro/2014, quando foi extinto, o Orkut fez também parte da nossa pesquisa, já que era uma das possibilidades de interação online para pessoas vivendo com HIV/Aids.

${ }^{3}$ WhatsApp Messenger é um app de mensagens instantâneas e chamadas de voz para dispositivos móveis. Scruff é também um app para dispositivos móveis, mas direcionado ao público gay, bissexual ou simpatizante. Torna viável a localização de possíveis parceiros para encontros sexuais e afetivos por meio do mapeamento de geolocalização (GPS - Global Positioning System).

${ }^{4}$ Buscamos manter a forma e estilo das narrativas, produzidas de forma online, como também o anonimato de seus autores.

${ }^{5}$ Embora os nicks, ou apelidos, sejam públicos (ou seja, qualquer um pode se apropriar deles), são utilizados nessas salas de bate-papo com o objetivo de preservar o anonimato dos seus usuários. Por questões éticas, optou-se por não utilizá-los aqui em sua forma original, já que eles aparecem de forma frequente nessas salas, implicando uma identidade daqueles que fazem uso deles na plataforma.

${ }^{6}$ L.A.V. da Silva coordenou a pesquisa, participando do trabalho de campo, análise de dados, redação do artigo e revisão crítica relevante do conteúdo intelectual. F.M. Duarte participou da pesquisa de campo, análise de dados, redação do artigo e revisão crítica relevante do conteúdo intelectual. G. R. Alves Netto participou da pesquisa de campo, redação do artigo e revisão crítica relevante do conteúdo intelectual.

Os autores agradecem ao CNPq, por financiar o projeto "Sociabilidades de jovens vivendo com HIV/ Aids: repercussōes e efeitos da soroidentidade", viabilizando a produção deste artigo; aos pesquisadores Adriana Miranda Pimentel, José Carlos Oliveira Chaves e Melquisedec Ferreira da Silva Santos, por contribuírem nas discussões e pesquisa de campo; aos bolsistas de iniciação científica Antônio Rafael Santana, Amanda Silva e Camila Moraes, por contribuírem, em diferentes momentos do projeto, com o acompanhamento das redes sociais; ao Centro Estadual Especializado em Diagnóstico, Assistência e Pesquisa (CEDAP), em Salvador, pela parceria durante a pesquisa de campo; è à Rede Nacional de Adolescentes e Jovens Vivendo com HIV/Aids, pelo acolhimento e divulgação do projeto. 
"Positive" sociabilities network: youth narratives on HIVIAids and their everyday tensions

From a qualitative research on sociabilities of young people living with HIV/Aids, this article presents some reflections on the place and importance of new social networks for young people living with HIV/Aids, highlighting some conflicts, dilemmas and tensions in daily issues related to HIV/Aids. Between 2012 and 2014, some online discussion groups and social networks that bring together people living with HIV/Aids were identified and monitored. In this article, through participant observation and online semistructured interviews, we highlight the existence of online support groups managed by people living with HIV/Aids, in order to obtain information, advice and support, even if, in addition to emotional support and information, there is the possibility of reproduction of moral values. It is emphasized that the technologies have brought new types of sociabilities and forms of social organization, produced from health criteria and biological characteristics (somatic). New ways of "social mobilization" are also being made possible through the internet: new commitments and senses of belonging that seem to be more transient, personal, diffuse or "liquid". In turn, these new forms of sociability also show the multiple ways of living with HIV/Aids.

> Keywords: HIVIAids; youth living with HIVIAids; internet; biosociability; care. 